\title{
Diez años sin Manolo: Epílogo para náufragos desde las antípodas
}

\author{
JOSÉ COLMEIRO
}

Un libro es una botella lanzada al mar sobre la cual es preciso pegar esta etiqueta: Que la atrape quien pueda

Alfred de Vigny

En el "Epílogo para ahogados", poema con el que concluye el libro A la sombra de las muchachas sin flor (1973), una extraña voz poética correspondiente a un hipocarpo sentenciaba crípticamente la máxima de que "es preciso elegir entre memoria y deseo". Esa aparente tensión se puede decir que resuena con insistencia a lo largo de toda la obra de Vázquez Montalbán, y de hecho da título a la recopilación de su obra poética completa. Se trata de una relación dialéctica entre memoria y deseo, pasado y futuro, historia y vida, que a menudo se ha manifestado en el binomio revolucionario generacional Marat/Sade, de cambiar la historia /cambiar la vida. El compromiso con la historia, con la realidad social, con la tribu, con la memoria individual y colectiva, se manifiesta en la necesidad de comunicar, de intervenir en la realidad, de dar voz, de servir de escriba de la realidad. Y también de dar una respuesta crítica e imaginar otra realidad posible. Porque cambiar la vida también significa el deseo de huida, de romper con las ataduras y los atavismos, de sueños, de ilusiones, de viajes, a otros horizontes, a otros mundos y otros confines. Un deseo de finalidad y de búsqueda de límites. Esas tendencias representan aristas de esos dos polos en los que se mueve toda la obra de Vázquez Montalbán, entre la memoria y el deseo. No necesariamente en contradicción, ya que quizás, como comentó en cierta ocasión Carlos Fuentes, "el pasado está vivo en la memoria, el futuro presente en el deseo" (Cebrián).

En la novela Los pájaros de Bangkok, publicada hace ya treinta años, Pepe Carvalho le preguntaba retóricamente a una potencial clienta que regateaba las condiciones del contrato para ir a investigar la desaparición de su hija en Tailandia: "-En qué cabeza cabe que un profesional deje su 
trabajo, su oficina, sus obligaciones, para coger un avión y plantarse en las antípodas." (Bangkok 122).

Y hace justamente ahora diez años Manolo Vázquez Montalbán regresaba de un largo viaje austral a las antípodas. Había ido a Australia y Nueva Zelanda para realizar una gira de conferencias. Aprovechó para realizar una breve estancia en Auckland como "escritor en residencia" de la Fundación Vista Linda, invitado por los presidentes de la misma, Antonio Regueiro y Jayne McKelvie. Allí en las antípodas terminó de perfilar sus últimas obras Milenio Carvalho y La aznaridad. De hecho su última novela, y la última entrega de la serie Carvalho, lleva por título precisamente Milenio Carvalho: Desde las antípodas. En aquella novela, Carvalho le confesaba a Biscuter el continuo poder de atracción del polo Sur: "-Otra vez la tentación de las Antípodas" (242).

En otra novela anterior publicada dos años antes, Erec y Enide, uno de sus personajes, Myrna Taylor, una muy viajada profesora británica de estudios hispánicos a punto de jubilarse, se explayaba también sobre su deseo de viajar y de explicar "por qué es importante contemplar el mundo desde las antípodas, sean las antípodas que sean" (192).

Intuyo que esta manifiesta y reiterada atracción por las antípodas refleja una actitud vital y una necesidad intelectual, de viajar, de escapar, de conocer, de explorar que Manolo tuvo a lo largo de su vida. Es un deseo de huida, pero también de descubrimiento y obsesión por llegar hasta el final de las cosas. Es la atracción del límite, el deseo imposible de plenitud, pero también, llegar a ver el mundo desde las antípodas es plantear otra mirada, hacernos ver la realidad desde un punto de vista alternativo, periférico, descentrado. En cierta medida, representa igualmente la búsqueda del paraíso, una utopía que casi siempre ha sido representada en forma de isla, ese lugar soñado del que no quisiéramos regresar.

10 años más tarde, me encuentro ahora yo haciendo ese mismo viaje de regreso. También yo he ido a ver el mundo desde las antípodas, y después de vivir casi 4 años al pie de la bahía de Auckland, rodeado de majestuosas islas volcánicas y tan apartado del resto del mundo, entiendo mucho mejor esa especial atracción del lejano Sur, tan remoto e inaccesible, esa necesidad vital de salir de los límites conocidos, de ver la vida desde la larga distancia, y con otros ojos nuevos, con una engrandecida visión periférica. Se nota no solo en la especial intensidad de la luz y la vivacidad del color, sino en otra energía y otra forma de ver la vida, qui- 
zás al revés, un poco como en los chistes, con la cabeza abajo. Pero el mapa del mundo visto al revés, centrado en el Sur, nos hace ver efectivamente las cosas de otra forma y con otro sentido. Y nos hace recordar que el Sur también existe, según nos instaba Mario Benedetti. Desde la distancia, lo que antes nos podían parecer temas de importancia se ven ahora empequeñecidos o absurdos (o casi triviales, como el tinglado de la cacareada Marca España o la nuevamente fracasada Expedición Malaspina alrededor del mundo). Y otras cosas que quizás casi ni apreciábamos porque se daban por descontado (los valores democráticos, los avances sociales, la justicia, la solidaridad, los derechos básicos), de repente cobran mucha mayor importancia.

Por todo ello, como sostiene el dicho clásico que Manolo solía mencionar, navigare neccesum est, vivere non necessum, que señalaba la esencial necesidad vital del viaje. Para Manolo el viaje era por una parte una gran pasión vital, y por otro un leitmotiv literario que subyace a toda su obra, y que resulta especialmente evidente incluso en los propios títulos de muchas de sus obras, como Los pájaros de Bangkok, Los mares del Sur, La Rosa de Alejandría, Quinteto de Buenos Aires, Pero el viajero que huye, o la mencionada Milenio, ese gran viaje de despedida final al fin del mundo. En esta búsqueda continua de nuevos horizontes, Manolo seguía en cierta manera el ejemplo del pintor postimpresionista Paul Gauguin, ese viajero utópico y atópico, que salió de Bretaña para encontrar su destino en las antípodas de Tahití, toda una simbólica propuesta de viajero fugitivo, al que Manolo dedicó gran atención en su obra, y que de hecho dio título a uno de sus primeros poemas ("Gauguin" en la sección "Liquidación de restos de serie" de Una educación sentimental) y a un libro de pintura dedicado al pintor y a su búsqueda del paraíso en los Mares del Sur, a quien calificó como "el fugitivo más simbólico de la modernidad" (Gauguin 2).

Se podría decir que el viaje siempre responde a una misma búsqueda mítica de ese lugar del que no querer regresar. Y las islas del Pacífico Sur, mitologizadas por la literatura y después por el cine, han sido tradicionalmente representadas como el último paraíso terrestre. Su belleza virginal, sus remotos paisajes recónditos, su naturaleza de flora y animales desconocidos, y con nombres igualmente desconocidos, y la lejanía cultural de sus habitantes con respecto a la civilización occidental, conjuran una atractiva promesa que invita al sueño de otra vida posible. Una constelación de miles de islas de esa gran Polinesia que conforman un 
gigantesco triángulo en el océano Pacífico, cuyos vértices serían las costas de Hawaii en el extremo Norte y en sus extremos Sur, Rapa Nui/Isla de Pascua al Este y Aoteaoroa/Nueva Zelanda al Oeste, la tierra de la Gran Nube Blanca en la mitología maorí.

En ese gran territorio mítico se sitúa La isla misteriosa de Julio Verne, que tiene al náufrago Cirrus Smith como protagonista, y al Capitán Nemo como invisible pero omnipresente deus ex machina que se comunica silenciosamente por sus actos. La isla misteriosa de Verne es a su vez heredera de otra isla mítica, la isla de Robinson Crusoe, creada por la imaginación ilustrada de William Defoe, que es el referente clásico de toda una tradición literaria de náufragos en islas desiertas, un género que en inglés se llama precisamente la Robinsonade. Este género moderno conforma una parábola del naufragio, que fluctúa entre el idealismo de la razón ilustrada de Defoe y el positivismo científico de Verne, y es una parábola que Manolo utilizó también como leitmotiv recurrente a lo largo de su obra, aunque frecuentemente relativizada desde la ironía o el escepticismo. De hecho un moderno Robinsón naúfrago es el protagonista y narrador de su libro Reflexiones de Robinsón ante un bacalao, y el texto mismo constituye una sucesión de mensajes de náufrago enviados desde una isla desierta a sus futuros lectores, que somos ahora nosotros mismos. De manera paradójica e irónica al mismo tiempo, los mensajes que emite son un recetario de comidas soñadas e imposibles de realizar en la isla desierta, pero escritos necesarios para mantener su razón.

Manolo acostumbraba a explicar la labor del escritor y del intelectual en la moderna sociedad de masas como la de un emisor de mensajes en busca de lectores cómplices capaces de descodificarlos. Para ello utilizaba frecuentemente esa metáfora del náufrago robinsoniano que envía mensajes en una botella con la esperanza de que alguien, en algún lugar, en algún momento, los encuentre y los pueda descifrar, y ser así su cómplice interlocutor. ${ }^{1}$

Era sin duda una manera de sentirse vivo, útil, conectado, de comunicar en suma, y de alguna manera poder intervenir en la realidad externa por medio de la palabra, para escapar de la isla en la que todo escritor

\footnotetext{
${ }^{1}$ Como ha señalado Kay Pritchett, "Montalbán reconoce el decisivo papel del lector como intérprete de textos. Para el poeta barcelonés, la formación del mensaje es un proceso de negociación entre emisor y receptor" (118).
} 
vive, máxime cuando tiene conciencia de su situación de alienante subnormalidad.

$\mathrm{Y}$ es así que Manolo ya consideraba como tempranos "mensajes de náufrago" aquellos mensajes que enviaba codificados desde las páginas de la revista Hogares modernos hacia finales de los años sesenta, travestido de "Jack el decorador", en busca de un interlocutor que los pudiera descodificar para aliviar su condición de intelectual subnormal y alienado, sometido a la necesidad de escribir artículos por encargo para sobrevivir $^{2}$. Y como comprobaría reiteradamente una y otra vez, en su obra comunicativa, periodística y literaria, en ocasiones se producía efectivamente ese "milagro de la botella del náufrago" (Iribarren).

Como teórico de los medios de comunicación de masas, y autor del primer libro sobre el tema publicado en España, Informe sobre la Información (1963), y de otros importantes estudios posteriores como Las noticias y la información (1973) e Historia y Comunicación social (1980), Manolo conocía muy bien las teorías estructuralistas sobre la codificación del "mensaje", pero desconfiaba del estricto planteamiento formalista y la operación de vacío ideológico del estructuralismo. En cuanto al tan traído y llevado "mensaje", Manolo parece distanciarse de las viejas diatribas entre la literatura "con mensaje" o literatura comprometida engagé, y el estructuralismo formalista, que argumentaba en palabras de Marshall McLuhan que el mensaje es el medio ${ }^{3}$.

La importancia del medio a la hora de configurar el mensaje, de interpelar al interlocutor, y de construirlo, queda fuera de toda duda, como $-$

2 “yo durante muchos años viví a base de escribir en una revista de decoración que se llamaba Hogares Modernos y en esa revista me busqué un seudónimo que era Jack el Decorador, una broma evidentemente de Jack el Destripador, y a través de allí intentaba de enviar mensajes de náufrago" (Erba).

${ }^{3}$ Historia y comunicación social contiene una crítica fulminante a algunos de los planteamientos anacrónicos de McLuhan, sobre el papel determinante de la revolución comunicativa de la imprenta y su utilización como vehículo base de la comunicación social desde el Renacimiento, debido a "la pequeñez del mercado receptor de mensajes" (70). Montalbán critica que se adelanta varios siglos al momento en que la burguesía adopta la imprenta como vehículo de autolegitimización, en el siglo XVIII y XIX, y olvida otros factores importantes desde un punto de vista marxista, como "la relación dialéctica entre todo tipo de estructuras y la infraestructura" (73), incluyéndose ahí la lucha de clases y la concienciación obrera. La comunicación impresa tardó varios siglos en cuajar como vehículo de masas, como explica el autor en una recurrente metáfora: "la Imprenta tuvo que navegar a lo largo de los siglos XVI, XVII y XVIII como una precaria nave propensa a toda clase de naufragios" (73). 
asimismo la importancia de la tecnología en la capacidad de transformar modos de comunicación y comportamiento social. Pero Manolo sospechaba tanto del voluntarista utilitarismo literario, como de la asepsia ahistórica. Potenciar el envoltorio del medio en detrimento del contenido del mensaje sería tan equivocado como definir la calidad literaria de una obra por la mayor o menor bondad de su mensaje. Y si bien es cierto que un mensaje valioso no salva a una obra mediocre, una obra sin mensaje, no sería más que una "chuchería del espíritu", o una pirueta artística ensimismada (El ruido y la furia 53). ¿Pues para qué enviar un mensaje si no se tiene nada que decir?

La literatura debe comunicar y ser capaz de expresar una verdad literaria, así como transmitir una verdad histórica, lo contrario serían mensajes ensimismados sin receptor. Aunque, como Manolo reflexionaba, la literatura siempre es historificada desde el momento de su creación, porque nunca existe en un vacío histórico: "El tiempo se filtra por las rendijas de las escrituras aparentemente más herméticas, más ensimismadas" (El ruido y la furia 138).

Y es que en Vázquez Montalbán todo son mensajes. Su obra creativa, en todas sus variadas facetas, se podría decir que constituye efectivamente una gigantesca agencia de mensajería, desbordada por su propia excesiva producción. Una proliferación de inmoderados mensajes en género y número, que respondía tanto a su vasto conocimiento enciclopedista de la realidad como a su obsesión de necesidad comunicativa.

Las múltiples facetas de su vasta obra responden a diversas funciones del escritor frente a la vida y la historia. En parte se trata de la función del escritor como memorialista de un tiempo y de un lugar, como hábil poseedor del código comunicativo, al igual que aquel mítico Prometeo que había robado a los dioses el fuego del lenguaje y del conocimiento y lo había transmitido a los mortales como un instrumento para su emancipación, desde la constatación del poder de la palabra para reivindicar memorias y deseos, individuales y colectivos.

En la ficción de Vázquez Montalbán abundan los ejemplos de personajes que reclaman esta misma función, con diverso grado de éxito. Tal es el caso en El pianista (1985) del joven Andrés, un joven vendedor de periódicos en el barrio del Raval en una Barcelona de posguerra, impotente observador de la realidad e incapacitado por su origen social y deficiente educación para darle expresión literaria. Aunque sin recursos estéticos propios, Andrés encuentra en la literatura la fuerza moral necesaria 
para sobrevivir los tiempos de resistencia antifranquista. Andrés es lector de libros prohibidos y devocionario de la cultura impresa, pues como él afirma "los libros hay que respetarlos" (123). En su caso, sin embargo, esta "consagración del libro" (124) no es meramente un reflejo del logocentrismo dominante, sino que se debe a la potencialidad funcional del libro como forma de resistencia cultural frente al poder. Así Andrés entiende el compromiso con la memoria histórica como un compromiso con el futuro:

Me gustaría saber escribir como Vargas Vila, Fernández Flórez o Blasco Ibáñez para contar todo esto, porque nadie lo contará nunca y esta gente se morirá cuando se muera... Saber expresarse, saber poner por escrito lo que uno piensa y siente es como poder enviar mensajes de náufrago dentro de una botella a la posteridad. Cada barrio debería tener un poeta y un cronista, al menos, para que dentro de muchos años, en unos museos especiales, las gentes pudieran revivir por medio de la memoria. (138, énfasis añadido)

Por otro lado, los exiliados republicanos refugiados en Santo Domingo que aparecen en su novela Galíndez (1990) son descritos como robinsones atrapados. Tal es el caso de Martínez Ubago, calificado como un "heredero de una razón náufraga en una isla del Atlántico", y de María Ugarte, que escribía con "una letra para cartas de náufragos, metidas en una botella de verde opaco, casi negro, a la sombra de la mortecina penumbra tropical" (298-99). Y así otros muchos casos más que refuerzan ese sentimiento de naufragio de la razón y desesperado intento de comunicación.

Un caso sintomático especial es el de Alberto Cerrato, el protagonista narrador de su novela El estrangulador (1994), que se cree o se hace pasar por el estrangulador de Boston. Encerrado en una institución hospital-carcelaria por su provocadora resistencia a dejarse integrar dentro del sistema, Alberto Cerrato confiesa su metafórica condición de náufrago, irónicamente un metafórico estrangulador ahogado por el sistema, que ahora escribe para lanzar en una botella su mensaje al exterior: "He pasado los suficientes años en este establecimiento como para que ahora sea yo quien cuente la película y lance una botella del náufrago con mi mensaje, más allá de estos muros de ladrillo tostado, desde la contradicción vivida por una retención no justificada por la creencia en mi culpabilidad" (19). 
La obra de Vázquez Montalbán responde también en parte a la función del escritor como revelador de lo que se esconde tras el manto de las apariencias, la invisible presencia de la ideología como el aire transparente que se respira, la investigación del desorden del orden, y en definitiva el esclarecimiento "del porqué de este porqué", como decía elípticamente la célebre copla, "la gente quiere enterarse". Y como decía en su indispensable Panfleto desde el planeta de los simios (1995), cuando en los discursos mediáticos actuales "el envoltorio es el mensaje" (28), esto se hace necesario ahora más que nunca: "Puesto que estamos en una economía y en una realidad cultural de mercado no sólo somos consumidores de detergentes o de latas de cerveza con o sin alcohol, sino también de mensajes, de verdades, de ideología, de información" (51).

En este aspecto, destaca la labor del escritor como desvelador y crítico mordaz, instalado en la ironía e incluso el sarcasmo, fabulador de lo absurdo y lo real, emisor de mensajes y ruidos en el orden del sistema, y hasta a veces visionario profeta. Sus proclamas comunicativas y sus universos creados de poesía y ficción son una prueba del "desafecto a la realidad", así como del deseo y la limitación de poder cambiarla. Son mensajes de náufragos que buscan la complicidad de un interlocutor, de cualquier tiempo y lugar, quizás ese lugar imposible de hallar del que uno no quisiera regresar.

En el injustamente poco recordado pero terriblemente actual ensayo utópico y atípico, La palabra libre en la ciudad libre (1979), Vázquez Montalbán nos recordaba la capacidad de los grupos sociales oprimidos y marginados de hacerse oír, para resquebrajar los unilaterales mensajes del sistema dirigidos sin posibilidad de feedback comunicativo: "Tal vez dispongan de los 'ruidos' y sean los ruidos de las manifestaciones, de la contrainformación la única posibilidad de respuesta frente a la conspiración del mensaje" (19). Frente a la comunicación dirigida del sistema, y frente al (des)orden establecido por el poder hegemónico, se oponen los ruidos que surgen de la calle, del pensamiento crítico y los grupos desposeídos de poder.

Frente a esa "conspiración del mensaje" por parte del poder, Vázquez Montalbán ya había adelantado su propia utopía democrática, una ciudad donde todos sus ciudadanos disponían de los medios de libre expresión e información, tenían una voz pública, como forma de contestación al sistema. Así en el epílogo de La palabra libre en la ciudad libre, fechado en 1974, en el período inmediato tras la revolución de 
abril en Portugal, el autor expresaba la utopía de la palabra y la imagen verdaderamente libres. En él se anticipaba varias décadas a la revolución comunicativa digital que vendría con los últimos años del milenio y la posibilidad de su instrumentalización como forma de movilización y resistencia colectiva a nivel global ${ }^{4}$. En aquel futurista panorama de "la ciudad libre" se imaginaba una globalización tecnológica y comunicativa, hoy en día plenamente alcanzada: la creación de una "ciudad global comunicacionalmente omnipotente" (126), "una posible ciudad global, universal"; la "multipolaridad de los centros de emisión de mensaje" (124); "el teléfono visual, convertido en servicio público al alcance de todos los habitantes de la ciudad libre" (143); "cualquiera puede grabar su propio mensaje televisivo en un cassette y en teoría cualquiera puede reclamar que las cámaras de televisión le enfoquen en su parcela de realidad" (124); y "que cada cual pueda tener en su balcón un pequeño mural electrónico donde abastece al público de su propia interpretación de la noticia o noticias que el ciudadano considera imprescindible transmitir" (142).

En otra ocasión más cercana, se expresaba sobre el enorme espacio comunicativo generado por las nuevas tecnologías y las posibilidades de intervenir y participar en los discursos públicos a través de estos nuevos canales:

Ahora mismo se está en discusión del sentido de la democracia participativa en una etapa en que los mecanismos de participación no son los mismos que se dieron en el origen de esa propuesta, en una situación en que te puedes comunicar por autopistas de información, por fax, etc. La capacidad de comunicar mensajes y participar en un gran mercado mundial del mensaje está muy abierta. (El ruido 105-106)

Ponía así de relieve la capacidad de contestar al sistema, enviando mensajes, y generando ruidos. Esa misma estrategia del ruido funcionaba como el elemento estructurador central de su monumental novela de la memoria Autobiografía del general Franco. En esta novela, la memoria de la resistencia antifranquista protagonizada por Marcial Pombo -otro intelectual frustrado de los muchos que aparecen en su obra, encargado de escribir la ficticia autobiografía del dictador- actuaba como un ruido

\footnotetext{
${ }^{4}$ Para un análisis ejemplar de la aplicación de las teorías comunicativas montalbanianas a la situación sociopolítica española a partir del 11-M, véase el ensayo de Francie CateArries.
} 
constante, una interferencia en el mensaje emitido por el monolítico discurso hegemónico del generalísimo, y en la historiografía oficial.

Igualmente, en El estrangulador, un intelectual subnormal como Cerrato, autolegitimado por sus vastos conocimientos enciclopédicos y por su posesión de los códigos del lenguaje científico, reitera su derecho al ruido como estrategia comunicativa: "según los especialistas en Teoría de la Comunicación, funciona un canal normalizado de mensajes y de pronto un mensaje inconveniente se cuela en él y funciona como un ruido..." (93); y reconoce irónicamente que "el medio es casi el mensaje, siempre que haga trampas" (125). En Panfleto, es el propio autor el que lanza los mensajes sin necesidad de máscaras ficcionales: "toda crítica se convierte en un ruido subversivo, desestabilizador, que distorsiona el efecto del mensaje" (43), y es por ello que el sistema ve necesario "matar al mensajero ruidoso" (46).

Y es que en Vázquez Montalbán todo son mensajes con mensaje. El autor toma clara conciencia de que los intelectuales, especialmente en una sociedad de consumo de capitalismo tardío, no pueden quedarse fuera, alejados de la sociedad, sino que deben intervenir y participar activamente en su transformación. Su fuerte compromiso ético y su conciencia de la responsabilidad social del escritor, de recordar el pasado, de hacer la crónica del presente, y dar voz a los sin voz, dependía de su capacidad básica de lograr la comunicación y de instrumentalizar el medio. Vázquez Montalbán se basó en los planteamientos del teórico marxista italiano Antonio Gramsci para utilizar la cultura popular como un instrumento de rebelión contra las fuerzas hegemónicas dominantes de la sociedad, convirtiendo el medio en contra de sí mismo. Esta práctica contra-hegemónica tendría el efecto de desmarginalizar los géneros populares, tradicionalmente considerados inferiores y subliterarios, y dotarlos de una nueva instrumentalidad discursiva.

Claro que la obra de Vázquez Montalbán resulta casi inabarcable, por su extensión y su diversidad. Más que una mensajería, se asemeja a una gigantesca y laberíntica biblioteca babilónica. Vázquez Montalbán nunca dejó de pensar y escribir, en un inmenso afán por intervenir activamente como intelectual en la sociedad, llevar su voz crítica a la plaza pública y participar en la construcción de una sociedad más libre, más justa y solidaria. Aparte del centenar de libros de novela, ensayo, poesía, y otros géneros heterogéneos e inclasificables, están sus numerosísimas colaboraciones periodísticas, las columnas, los artículos de crítica, los prólogos, 
entrevistas y demás intervenciones públicas, que suman varios miles de títulos aparecidos en revistas, periódicos, libros, y otros medios. Por no hablar de las traducciones, las antologías, las reediciones y las múltiples adaptaciones de sus obras, que estos días estamos revisitando. Todo un universo de mensajes que desafían su aprehensión.

Eran mensajes de náufrago, sin duda, pero con la perspectiva del tiempo se va haciendo también cada vez más clara otra realidad: la de que en realidad los náufragos somos nosotros, puesto que todos vivimos en islas y necesitamos las botellas de mensajes como balones de oxígeno para no perecer ahogados entre los restos del naufragio colectivo. Por ello Manolo se nos muestra ahora como un fantasmagórico Capitán Nemo, invisible pero real, que nos sigue enviando mensajes "desde la otra orilla del horizonte". El Capitán Nemo era también un personaje querido de Manolo, que aparecía ya en Cuestiones marxistas (1974), junto a Carlos, Groucho y el resto de la heterodoxa familia Marx, y que tuvo su último avatar precisamente en Milenio Carvalho, como "un antiguo líder ecologista y pacifista alemán", "un sabio empeñado en salvar el mundo y que se hace llamar capitán Nemo" (II, 74), transformado en un utópico luchador a bordo de un nuevo Nautilus con destino a otro planeta desconocido. La obra de Manolo en efecto sigue emitiendo mensajes, como el invisible Capitán Nemo; sus palabras siguen echándonos cabos, orientando nuestros pasos desde la otra orilla. Su obra, como su memoria, se mantiene, adquiriendo nueva profundidad y resonancia, provocándonos y alentándonos, en cualquier orilla en que nos encontremos, aquí o en las antípodas.

Las palabras de Vázquez Montalbán resuenan todavía hoy con enorme fuerza, frente al marasmo intelectual del nuevo milenio, el desánimo de la actualidad y la desorientación de la crisis -todas las crisis- no solo la económica y política, sino también la crisis de valores, de memorias, de pérdida de ilusiones, de grandes narrativas, y grandes proyectos. La pérdida de imaginarios, aquellas "siluetas de lo que sabíamos y en lo que creíamos", como mencionaba al principio del Panfleto desde el planeta de los simios (9). "Nada quedó de Abril" decía el poema inicial de su primer poemario Una educación sentimental, y lo contestaba tres décadas más tarde como "Definitivamente nada quedó de Abril", el poema de Pero el viajero que huye que ponía punto final al ciclo poético de Memoria y Deseo. Ante toda esta colección de fracasos colectivos, es necesario preguntarse, con Joaquín Sabina, ese otro Pepe Carvalho disfrazado con 
bastón y bombín: ¿Quién nos ha robado el mes de abril, ese mes más cruel? Si nos quitan el mes de abril, nos quitan los sueños, las esperanzas, las ilusiones, los deseos de una vida y un mundo mejores. ¿Pues qué quedó del mes de abril? Quizás nos queda la memoria de lo que pudo haber sido y no fue; las ruinas de la ciudad de los deseos, con la progresiva desaparición de los grandes ideales de emancipación, de justicia y equidad social, la erosión de los derechos conquistados a través de décadas de luchas sociales, ante el establecimiento de la feroz dictadura de los mercados. Pero nos quedan también las palabras libres y la posibilidad de hacer ruido con ellas.

La huella de la obra de Vázquez Montalbán es profunda. Nos ha dejado treinta años de Pepe Carvalho rebuscando en las basuras del sistema, persiguiendo sombras, testigo de una desencantada transición y de un fin de milenio todavía más desencantado. Y miles de páginas de novelas, artículos, ensayos, versos... Cientos de miles de palabras. Sus comentarios y reflexiones, lúcidas e irónicas, han ayudado a muchos a convivir con la realidad, a alumbrar la oscuridad de la caverna y explicarnos el desorden del orden, a no aceptar la inevitabilidad de las apariencias de la realidad, una realidad que cada vez parece volverse más esperpéntica e irreconocible. Frente al silencio y la oscuridad, la erosión de la memoria, la falsificación de la realidad proyectada en la caverna platónica, y la imposición del pensamiento neoliberal como única gran verdad universal, nos quedan los ecos de sus palabras que todavía resuenan con fuerza.

$\mathrm{Su}$ pensamiento sigue siendo útil y necesario para entender el desorden del orden en nuestra actualidad. Porque su aguda visión sigue ofreciendo motivos de reflexión para los nuevos tiempos que corren. Necesitamos volver a Carvalho, a Groucho, a Galíndez, al pianista, al polaco, al escriba sentado, al cronista, y al estrangulador en estos malos tiempos para la lírica y para la épica, hoy más que nunca. En estos indignados e indignantes tiempos de sálvese quien pueda, sus palabras resuenan como antídoto a la desorientación, a la crisis de los imaginarios y a la borradura de la memoria y de la historia. Del porqué de este porqué la gente quiere enterarse. ¿Cuál es el pasado de este presente? ¿Hay otro futuro posible? ¿Sobre qué memorias y qué deseos se puede construir? El otro lado del desencanto es la lucidez. Sus palabras siguen buscando nuevas alternativas a la dictadura del economicismo neoliberal, palabras de re- 
sistencia frente a la nueva cultura del poder, de oposición al final de la historia sin final feliz.

El tiempo le ha dado la razón a Vázquez Montalbán y a Groucho y a Carvalho y a Bogart y a Cerrato y a Rosell: el final feliz que nos habían prometido era un timo, nada más que un engaño colorido, un chupón de menta para tranquilizar conciencias, con la promesa de un nuevo orden universal que nos haría más ricos, más libres y más felices. La realidad que se nos muestra es bien diferente y la contestación frente el sistema sigue siendo una imperiosa necesidad ética.

Es cierto que todo conocimiento es parcial y fragmentario, que no existen las grandes verdades y las grandes narrativas de la historia son fallidas. Los límites de nuestro conocimiento sobre una realidad fragmentaria, frágil y transitoria, quedaban resumidos en los versos de $L a$ tierra baldía de T.S. Eliot: "tú solo conoces un puñado de imágenes rotas, sobre las que se pone el sol" (31). Y sin embargo, a pesar de ello, todas las preguntas siguen ahí. El célebre binomio Marat/Sade, que presentaba la aparente disyuntiva de cambiar la vida/cambiar la historia actúa como un impulso vital que recorre toda la obra montalbaniana, aun a sabiendas de las contradicciones, limitaciones y obstáculos para lograrlo, desde la duda y la ironía como mecanismos de acercamiento a la realidad, y una ratificación final: "el escepticismo de la razón sobre su propia capacidad de entender la vida, la Historia y cambiarlas" (El ruido y la furia 137). Y a pesar de todo ello, seguir en el empeño de buscar respuestas alternativas y otros mundos posibles.

Como Vázquez Montalbán solía recordar, siguiendo a Lewis Caroll en Alicia a través del espejo, las palabras tienen dueño. Es necesario apropiarse del lenguaje para dejar de ser esclavo. Como he mencionado con anterioridad, según la mitología clásica, Prometeo robó el fuego de los dioses para dárselo a los mortales. A manera de metáfora del robo robinhoodiano, se trataba de apoderarse de las palabras, sacarlas del recinto sagrado de los dioses y sus sacerdotes, para compartirlas con los demás. El intelectual comprometido, como nuevo Prometeo, arrebató el lenguaje al poder para dárselo a los que no tienen voz. El lenguaje es el instrumento del intelectual para conectar con los demás, explicar el mundo, intervenir en la realidad, verbalizar memorias y deseos.

Analizar la construcción colectiva del pasado, sus camuflajes, y sus olvidos, nos llevará a descubrir las claves de nuestro presente y por lo tanto las bases del futuro. Esa es la función primordial del escritor testi- 
monial. Y, en definitiva, cada uno de los capítulos de su dilatada obra no es sino uno de los múltiples envíos de "mensajes de náufrago dentro de una botella a la posteridad", esperando que alguien los recoja al otro lado de la orilla. Es aconsejable en este sentido recordar las palabras de Antonio Muñoz Molina, quien aseguraba que "la mejor literatura de la modernidad la han escrito los grandes robinsones urbanos" (El Robinson urbano 9). Nuestra lectura y nuestra respuesta son de alguna manera unas contestaciones dilatadas en el tiempo a aquellos "mensajes de náufrago" enviados por el Robinson urbano que Montalbán creó a través de su obra, mensajes ahora recuperados y revitalizados después del largo viaje metafórico desde el otro lado del océano.

Resuenan de nuevo las palabras de Andrés, el joven vendedor de periódicos del Raval, y el eslabón más débil de la cadena transmisora de mensajes oficiales. En su caso Memoria y deseo, son las dos caras de una misma necesidad comunicativa: "Saber expresarse, saber poner por escrito lo que uno piensa y siente es como poder enviar mensajes de náufrago dentro de una botella a la posteridad. Cada barrio debería tener un poeta y un cronista, al menos, para que dentro de muchos años, en unos museos especiales, las gentes pudieran revivir por medio de la memoria" (énfasis añadido). Y ahora, puede decirse que Montalbán fue exactamente ese poeta y ese cronista, ya no Robinson naufragado, sino Capitán Nemo que nos sigue mandando mensajes.

Para completar este epílogo para viajeros náufragos, quisiera invocar precisamente las palabras del Manolo poeta. Como veíamos, en el "Epílogo para ahogados", poema final de A la sombra de las muchachas sin flor, se presentaba la aparente disyuntiva de "elegir entre memoria y deseo". Como el joven Andrés nos recuerda, sin embargo, es la mezcla de memoria y deseo la que da sentido a la vida, ese continuo viaje sin otro retorno que al propio origen. Y para cerrar el círculo, es apropiado recordar uno de los poemas de Pero el viajero que huye que nos habla del viaje final, de ese real y metafórico viaje hasta las antípodas, para volver al principio, desde la evidencia tantas veces constatada por Manolo de que, en palabras de T. S. Eliot, en mi final está mi principio:

Pero qué mar no vuelve sobre su propio rastro qué mar escapa a las redes azules del aire ensimismado 


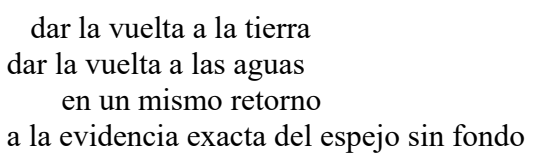

\section{Bibliografía}

Cate-Arries, Francie. "La palabra libre en la construcción de la ciudad libre: Reflexiones sobre Vázquez Montalbán y la 'noche de los móviles' del 13-M.” Manuel Vázquez Montalbán: El compromiso con la memoria. Ed. José F. Colmeiro. Woodbridge: Tamesis, 2007. 211225.

Cebrián, Juan Luis. "Memoria y deseo", El País. 12 de mayo, 2012. Web.

Colmeiro, José. El ruido y la furia: Conversaciones con Manuel Vázquez Montalbán, desde el planeta de los simios. Madrid: Editorial Iberoamericana, 2013.

Eliot, T.S. The Waste Land. Londres: Norton, 2013.

Erba, Roberta. "Los seudónimos de Vázquez Montalbán.” Vespito.net. (21 abril 1998).

Iribarren, María. "Manuel Vázquez Montalbán: 'La novela es una alternativa de lo real'." Magazín literario 6 (diciembre 1997).

Muñoz Molina, Antonio. El Robinson urbano. Barcelona: Seix Barral, 1993.

Pritchett, Kay. "Abriles, ahogados y otros recursos poéticos residuales en Pero el viajero que huye." Manuel Vázquez Montalbán: El compromiso con la memoria. Ed. José F. Colmeiro. Woodbridge: Tamesis, 2007. 117-127.

Vázquez Montalbán, Manuel. Una educación sentimental. Barcelona: Saturno, 1967.

. A la sombra de las muchachas sin flor. Barcelona: Saturno, 1973.

. Cuestiones marxistas. Barcelona: Anagrama, 1974.

- La palabra libre en la ciudad libre. 1974. Barcelona: Gedisa, 1979.

. Historia y comunicación social. 1980. Madrid: Alianza, 1985.

. Los pájaros de Bangkok. 1983. Barcelona: Planeta, 1986.

. El pianista. Barcelona: Seix Barral, 1985.

. Galíndez. Barcelona: Planeta, 1990.

. Gauguin. París: Flohic, 1991.

. Pero el viajero que huye. Madrid: Visor, 1991.

. Autobiografía del general Franco. Barcelona: Planeta, 1992. 
. El estrangulador. Barcelona: Mondadori, 1994.

. Panfleto desde el planeta de los simios. Barcelona: Crítica, 1995.

- La gula. Reflexiones de Robinsón ante un bacalao. Barcelona: Lumen, 1995.

- Memoria y deseo (1963-1990). 1991. Barcelona, Grijalbo/Mondadori, 1996.

. Erec y Enide. Barcelona: Planeta, 2002.

_. Milenio Carvalho. 2 volúmenes (1: Rumbo a Kabul; 2: En las antípodas). Barcelona: Planeta, 2004. 